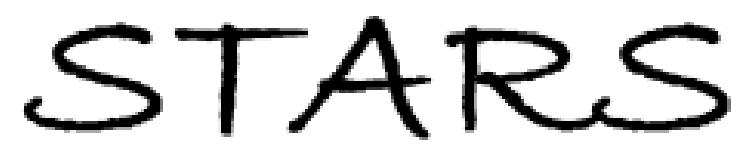

University of Central Florida

STARS

$1-1-2005$

\title{
Two-dimensional model for melting and vaporization during optical trepanning
}

D. Zeng

University of Central Florida

W. P. Latham

A. Kar

University of Central Florida

Find similar works at: https://stars.library.ucf.edu/facultybib2000

University of Central Florida Libraries http://library.ucf.edu

This Article is brought to you for free and open access by the Faculty Bibliography at STARS. It has been accepted for inclusion in Faculty Bibliography 2000s by an authorized administrator of STARS. For more information, please contact STARS@ucf.edu.

\section{Recommended Citation}

Zeng, D.; Latham, W. P.; and Kar, A., "Two-dimensional model for melting and vaporization during optical trepanning" (2005). Faculty Bibliography 2000s. 5825.

https://stars.library.ucf.edu/facultybib2000/5825

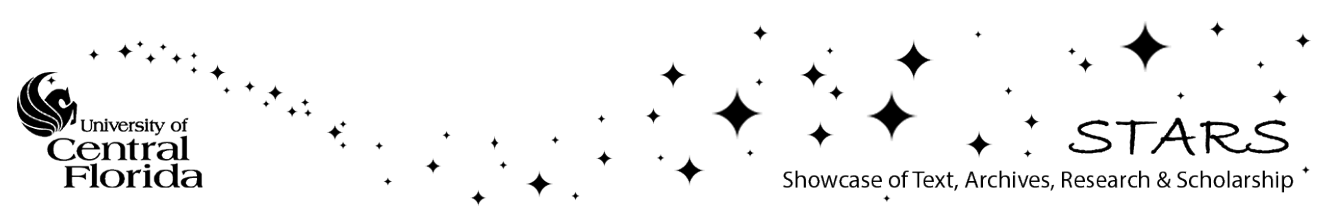




\section{Two-dimensional model for melting and vaporization during optical trepanning}

Cite as: J. Appl. Phys. 97, 104912 (2005); https://doi.org/10.1063/1.1897835

Submitted: 03 December 2004 . Accepted: 04 March 2005. Published Online: 05 May 2005

D. Zeng, W. P. Latham, and A. Kar

\section{ARTICLES YOU MAY BE INTERESTED IN}

Review on laser drilling I. Fundamentals, modeling, and simulation

Journal of Laser Applications 25, 012006 (2013); https://doi.org/10.2351/1.4773837

Laser drilling velocity in metals

Journal of Applied Physics 47, 5460 (1976); https://doi.org/10.1063/1.322578

One-dimensional steady-state model for damage by vaporization and liquid expulsion due to laser-material interaction

Journal of Applied Physics 62, 4579 (1987); https://doi.org/10.1063/1.339053

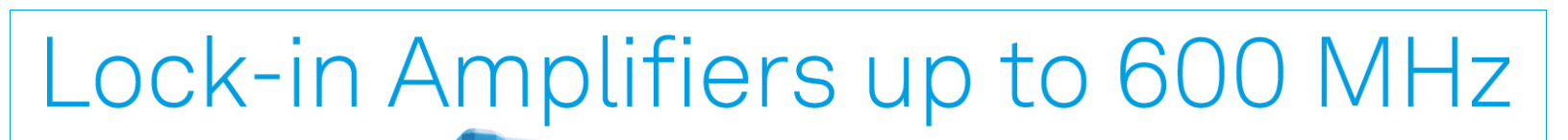

starting at

$$
\$ 6,210
$$

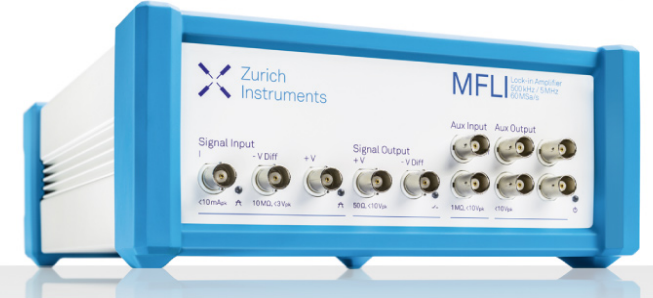

J. Appl. Phys. 97, 104912 (2005); https://doi.org/10.1063/1.1897835

(c) 2005 American Institute of Physics. 


\title{
Two-dimensional model for melting and vaporization during optical trepanning
}

\author{
D. Zeng \\ Laser-Aided Manufacturing, Materials and Microprocessing Laboratory (LAMMP), College of Optics and \\ Photonics, Center for Research and Education in Optics and Lasers (CREOL), Mechanical, Materials \\ and Aerospace Engineering Department, University of Central Florida, Orlando, Florida 32816 \\ W. P. Latham \\ Air Force Research Laboratory (AFRL) Division on Earth and Life Studies (DELS), 3550 Aberdeen Avenue \\ Southeast, Kirtland Air Force Base, Albuquerque, New Mexico 87117 \\ A. $\mathrm{Kar}^{\mathrm{a}}$ \\ Laser-Aided Manufacturing, Materials and Microprocessing Laboratory (LAMMP), College of Optics and \\ Photonics, Center for Research and Education in Optics and Lasers (CREOL), Mechanical, Materials \\ and Aerospace Engineering Department, University of Central Florida, Orlando, Florida 32816
}

(Received 3 December 2004; accepted 4 March 2005; published online 5 May 2005)

\begin{abstract}
Annular laser beams provide a drilling mechanism that can be referred to as optical trepanning. In this paper an analytical two-dimensional model is developed for optical trepanning. The analysis accounts for conduction in the solid, vaporization, and convection due to the melt flow caused by an assist gas. Based on the model, the influences of pulse duration, laser-pulse length, pulse repetition rate, intensity profiles, and beam radius are investigated to examine their effects on the recast layer thickness, hole depth, and taper. Deeper cavity depth, thicker recast layer, and larger taper are obtained with the increase in the laser intensity. By using different types of intensity profiles, the nature of the hole taper can be modified, i.e., convergent or divergent holes can be produced. The effects of the inner radius of annular beams are more significant than other laser parameters. An increase in the inner radius reduces the hole taper and produces thinner recast layer and deeper cavity depth. (C) 2005 American Institute of Physics. [DOI: 10.1063/1.1897835]
\end{abstract}

\section{INTRODUCTION}

Lasers have been used for melting and vaporizing materials for a variety of applications including microhole drilling. The aerospace industry, in particular, has been employing this technique for drilling large number of closely spaced cooling holes in turbine engine components such as airfoils, nozzle guide vanes, and combustion chambers. ${ }^{1,2}$ Percussion drilling and trepanning are two traditional laser drilling methods. Percussion drilling is accomplished by focusing the laser beam to approximately the required diameter of the hole, exposing the material to one or a series of laser pulses at the same spot to melt and vaporize the material. Major concerns in laser drilling are geometrical and metallurgical characteristics. ${ }^{3,4}$ Geometrical characteristics include hole size, taper, circularity, and repeatability, and metallurgical characteristics refer to heat-affected zone, recast layer, spatter formation, and microcracking. These characteristics are influenced by several factors including average laser power, pulse energy, pulse duration, pulse repetition rate, pulse temporal and spatial profiles, intensity profiles, focus settings, and optical as well as thermal properties of the workpiece. Effective utilization of lasers depends very much upon proper understanding of the effects of these factors.

Chen $e t a l .{ }^{5}$ examined the effects of laser peak power, pulse format, and wavelength for drilling three advanced materials: NiAl, N5, and SiC CMC, and observed that cracking

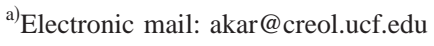

in NiAl was greatly reduced when high peak power with short laser format was used. Recast layers in all three materials were generally thinner when high peak powers, short pulse formats, or long pulse bursts were employed. Yilbas ${ }^{4}$ attempted to identify a few dominant process variables that affect the hole quality and reported that the effect of the location of the laser focal plane was very significant in most case, and that the taper formation in percussion laser drilling can be significantly reduced by suitable control of laser variables. Low et al. ${ }^{6}$ investigated the effects of assist gas on the physical characteristics of spatter formation during percussion laser drilling on NIMONIC 263 alloy by using a fiberoptic-delivered Nd:YAG (yttrium aluminum garnet) laser. $\mathrm{Ng}$ and $\mathrm{Li}^{7}$ studied the effects of laser peak power and pulse width on the repeatability of hole geometry and found that melt ejection and spatter formation contributed to the poor repeatability of the drilling process. Ghoreishi et al. ${ }^{8}$ investigated the effects of six controllable laser variables on the hole taper and circularity in percussion laser drilling of stainless steel workpiece and showed that the pulse width and peak power affected the hole diameter, taper, and circularity significantly, whereas, the pulse repetition rate had no effect on these three hole characteristics. Voisey et al. ${ }^{9}$ analyzed the melt ejection, angle of the ejecta trajectory, and molten layer thickness during laser drilling of metals. Kamlage et al. ${ }^{10}$ showed that at high laser intensity, well above the ablation 
threshold, femtosecond lasers can drill deep high-quality holes in metals without any postprocessing or special gas environment.

While considerable attention has been given to the percussion laser drilling, very few studies have been reported on laser trepanning. Drilling by trepanning involves cutting a hole by rotating a laser beam with an optical element or an $x-y$ galvoscanner. Optical elements are used to scan the beam in either spiral or circular orbits while maintaining the focused laser spot on the workpiece. Complex patterns can be produced in the workpiece using multiaxis machining systems including a galvoscanner to effectively mill away the material. These conventional trepanning processes can be referred to as mechanical trepanning. Circular laser spots are generally used in conventional laser drilling.

Annular laser beams provide a laser drilling mechanism. When an annular beam is focused on the workpiece surface, the material around the annulus laser spot is heated, melted, vaporized, and removed, leading to the formation of a hole. This process, which we refer to as optical trepanning, does not involve any rotating optics or rotating workpiece. An annular beam was found to be well suited for drilling good quality large diameter holes using a high power laser beam by Rioux et al. ${ }^{11}$ and Belanger and Rioux ${ }^{12}$ who combined an axicon lens and a convex lens to form an optical system producing an annular beam. In this paper, a two-dimensional model is presented for optical trepanning in which the effects of an assist gas on melt flow and convection heat transfer are considered. The effects of laser intensity, pulse duration, pulse repetition rate, beam radius, and three different laser intensity profiles, such as inner and outer half Gaussian beams with maximum intensities at the inner and outer radii of the annulus, respectively, and a full Gaussian beam with maximum intensity within the annulus, are investigated.

\section{MATHEMATICAL MODEL}

The optical trepanning process considered in this model is schematically illustrated in Fig. 1. An annular laser beam of intensity $I(r, t)$ is illuminated on the workpiece surface. Due to intense heat flux, the material around the annulus laser spot is heated, melted, and vaporized and the melt is removed by an assist gas. Melting and vaporization occur mainly within the annulus. Melting generally does not occur around the center of the annulus in optical trepanning. The melt expulsion and laser heating also affect the shape of the solid-liquid interface. The geometrical shapes of the liquidvapor and solid-liquid interfaces around the periphery of the annulus are shown in Fig. 1. The assist gas exerts a force on the melt and expels it upwards. This melt expulsion and laser vaporization create a cavity, i.e., a liquid-vapor interface.

The mathematical model utilizes the conservation of energy, i.e., the Stefan condition at the solid-liquid and liquidvapor interfaces, taking the effects of the liquid metal flow and the assist gas flow into account. The model is based on the following assumptions:

(1) No plasma is generated in the cavity. Only liquid metal and metal vapor are considered to form during the optical trepanning process.
(2) The temperature distribution in the liquid metal is assumed to be linear.

(3) The thermophysical properties of the liquid and solid phase are taken to be constant.

(4) Heat loss to the environment due to convection and surface radiation is neglected. This assumption leads to the determination of maximum material damage, i.e., maximum thermal effect of laser irradiation.

(5) The material removal from the melt layer is considered to be mainly due to the melt expulsion by the assist gas. The vaporization rate is considered negligible compared to the melt expulsion rate in the model.

(6) The temperature distribution in the solid phase is assumed to be locally one-dimensional and it is obtained under the quasisteady-state approximation.

(7) The shape of the cavity does not change during the laser-pulse-off time.

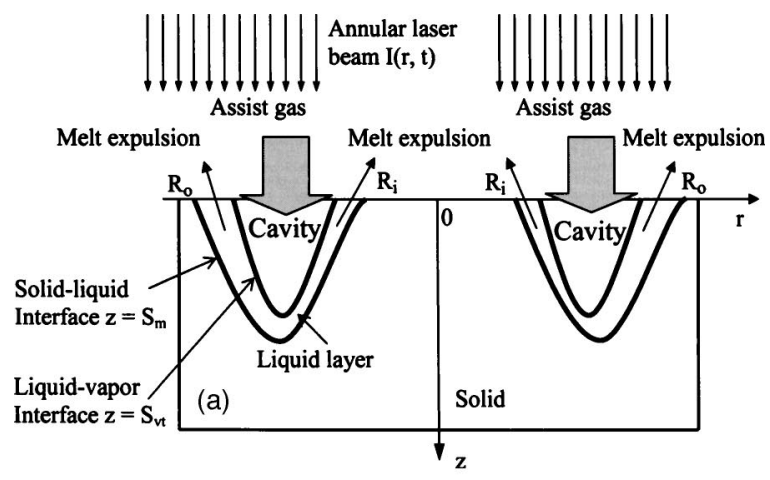

Laser beam I $(r, t)$
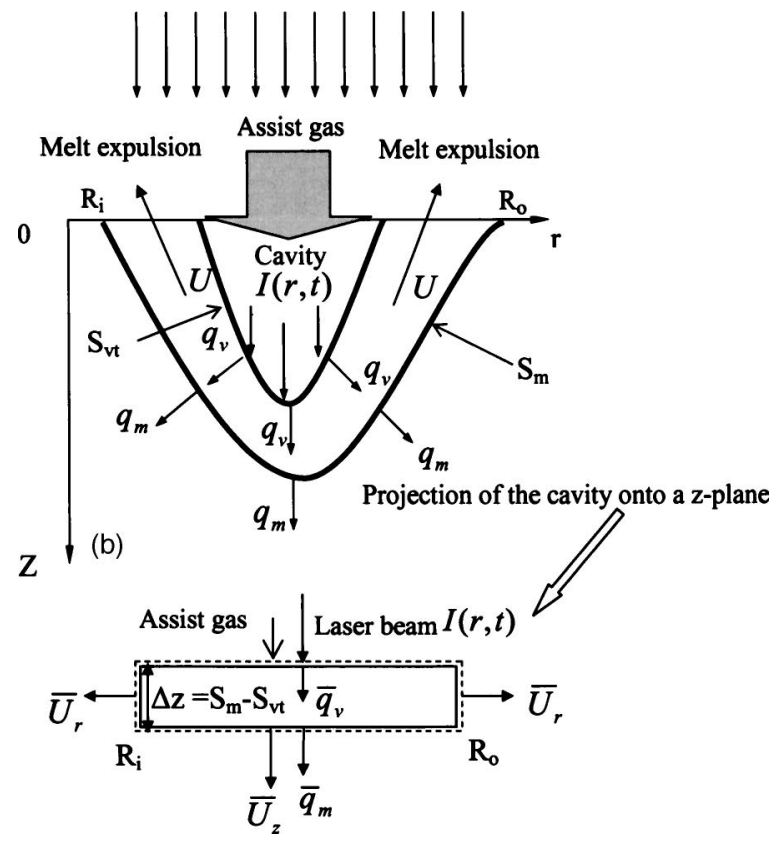

FIG. 1. (a) schematic diagram of the two-dimensional steady-state model for optical trepanning. (b) control volume for mass and energy balances in the liquid metal layer. 


\section{MATHEMATICAL FORMULATION}

\section{A. Energy balance at the interfaces}

Assuming that the solid-liquid (melting front) and liquid-vapor (vaporization front) interfaces have been formed, their geometrical shapes are expressed, respectively, as

$$
\begin{aligned}
& z=S_{\mathrm{vt}}(r, t), \\
& z=S_{m}(r, t),
\end{aligned}
$$

where $S_{\mathrm{vt}}$ and $S_{m}$ are the depths of vaporization and melting fronts, respectively. $S_{\mathrm{vt}}$ denotes the total depth of the cavity which is formed due to vaporization and liquid metal expulsion. At the solid-liquid interface $z=S_{m}$, the energy balance and boundary conditions can be expressed as ${ }^{13,14}$

$$
\begin{aligned}
-k_{l} \frac{\partial T_{l}}{\partial z}\left[1+\left(\frac{\partial S_{m}}{\partial r}\right)^{2}\right]= & -k_{s} \frac{\partial T_{s}}{\partial z}\left[1+\left(\frac{\partial S_{m}}{\partial r}\right)^{2}\right] \\
& +\rho_{s} L_{m} \frac{\partial S_{m}}{\partial t},
\end{aligned}
$$

$$
T_{l}=T_{s}=T_{m} \text { at } z=S_{m}(r, t),
$$

where $\rho_{s}$ is the density of the solid phase, $L_{m}$ is the latent heat of melting, $k_{l}$ and $k_{s}$ are the thermal conductivities of liquid and solid phases, respectively, $T_{l}$ and $T_{s}$ are the temperatures of liquid and solid phases, respectively.

At the liquid-vapor interface $z=S_{\mathrm{vt}}$, the energy balance and boundary conditions can be expressed as

$$
\begin{aligned}
& A I(r, t)+k_{l} \frac{\partial T_{l}}{\partial z}\left[1+\left(\frac{\partial S_{\mathrm{vt}}}{\partial r}\right)^{2}\right]=\rho_{l} L_{v} \frac{\partial S_{\mathrm{vv}}}{\partial t}, \\
& T_{l}=T_{\mathrm{st}} \text { at } z=S_{\mathrm{vt}}(r, t),
\end{aligned}
$$

where $\rho_{l}$ is the density of the liquid phase, $A$ is the absorptivity of the liquid metal for the incident laser beam, $I(r, t)$ is the laser intensity, $L_{v}$ is the latent heat of vaporization, $S_{\mathrm{vv}}$ is the cavity depth due to vaporization only.

$T_{\text {st }}$ can be estimated by the following expression ${ }^{15}$

$$
T_{\mathrm{st}}=A I \sqrt{\frac{4 t}{\pi \rho_{l} C_{\mathrm{eff}} k_{l}}},
$$

where $C_{\text {eff }}$ is the effective heat capacity that accounts for the latent heat of melting and the specific heat capacity of the substrate $C_{\mathrm{ps}}$, which is taken as

$$
C_{\mathrm{eff}}=C_{\mathrm{ps}}+\frac{L_{m}}{T_{m}} .
$$

It should be noted that this model is based on an assumption that the melt layer is continuously expelled, but Eq. (7) assumes heat conduction in a stationary liquid layer.

\section{B. Heat conduction in the solid phase}

To simplify the heat conduction analysis in the solid phase, a one-dimensional heat diffusion model is assumed,

$$
\begin{aligned}
& \frac{\partial T_{s}}{\partial t}=\alpha_{s} \frac{\partial^{2} T_{s}}{\partial z^{2}}, \\
& T_{s}=T_{m} \text { at } z=S_{m}(r, t),
\end{aligned}
$$

where $\alpha_{s}$ is the thermal diffusivity of the solid phase.

Letting $z^{\prime}=z-\dot{S}_{m}(r, t)$, where $\dot{S}_{m}(t)$ is the velocity of the melting front along the $z$ direction. Equation (9) can be written in a moving coordinate system with the origin being fixed at the solid-liquid interface, and then, under quasisteady-state condition, ${ }^{16}$ the temperature distribution in the solid phase can be obtained as follows:

$$
T_{s}=T_{0}+\left(T_{m}-T_{0}\right) \exp \left\{-\frac{\dot{S}_{m}(r, t)}{\alpha_{s}}\left[z-S_{m}(r, t)\right]\right\} .
$$

\section{Mass and energy balances in the liquid metal layer}

Following the conservation of mass and assumption (5), the amount of material melted at the solid-liquid interface is equated to the sum of the amount of melt expelled by the assist gas through the inner and outer surfaces of an annular control volume of inner and outer radii $R_{i}$ and $R_{o}$, respectively, and thickness $\Delta z$, as shown in Fig. 1(b). This control volume is obtained by projecting the melt layer onto a plane parallel to the radial direction.

$$
\begin{aligned}
\pi \rho_{l} \bar{U}_{z}\left(R_{o}^{2}-R_{i}^{2}\right)= & 2 \pi \rho_{l} \bar{U}_{r} R_{i}\left(S_{m}-S_{\mathrm{vt}}\right)+2 \pi \rho_{l} \bar{U}_{r} R_{o}\left(S_{m}\right. \\
& \left.-S_{\mathrm{vt}}\right)
\end{aligned}
$$

where $\bar{U}_{z}$ and $\bar{U}_{r}$ are the average velocities of the liquid metal along the $z$ and $r$ directions, respectively. Equation (12) can be simplified as

$$
\bar{U}_{z}\left(R_{o}-R_{i}\right)=2 \bar{U}_{r}\left(S_{m}-S_{\mathrm{vt}}\right) .
$$

Similarly, the energy balance for the melt layer can be written as

$$
\begin{aligned}
& \bar{q}_{v} \pi\left(R_{o}^{2}-R_{i}^{2}\right)-\bar{q}_{m} \pi\left(R_{o}^{2}-R_{i}^{2}\right)=2 \pi r_{o}\left(S_{m}-S_{\mathrm{vt}}\right) \rho_{l} C_{\mathrm{pl}} \bar{U}_{r} \bar{T}_{l} \\
& \quad+2 \pi r_{i}\left(S_{m}-S_{\mathrm{vt}}\right) \rho_{l} C_{\mathrm{pl}} \bar{U}_{r} \bar{T}_{l}
\end{aligned}
$$

where $\bar{q}_{v}$ and $\bar{q}_{m}$ are the average heat fluxes at the vaporization and melting fronts, respectively, $C_{\mathrm{pl}}$ is the specific heat capacity of the liquid phase, and $\bar{T}_{l}$ is the average temperature of the melt layer. $\bar{T}_{l}$ and $\bar{q}_{m}$ can be approximated as

$$
\bar{T}_{l}=\frac{T_{\mathrm{st}}+T_{m}}{2}
$$

and

$$
\bar{q}_{m}=\frac{\left(\bar{T}_{l}-T_{m}\right) k_{l}}{\left(S_{m}-S_{\mathrm{vt}}\right)} .
$$


By substituting Eq. (16) into Eq. (14), the following expression is obtained:

$$
\bar{q}_{v}=k_{l} \frac{T_{\mathrm{st}}-T_{m}}{S_{m}-S_{\mathrm{vt}}}+\frac{\left(S_{m}-S_{\mathrm{vt}}\right)\left(T_{\mathrm{st}}+T_{m}\right)}{R_{o}-R_{i}} \rho_{l} C_{\mathrm{pl}} \bar{U}_{r} .
$$

The average velocity profile of the liquid metal in the radial direction can be estimated as ${ }^{14}$

$$
\bar{U}_{r}=\frac{\tau_{i}}{2 \mu}\left(S_{m}-S_{\mathrm{vt}}\right)
$$

where $\tau_{i}$ is the shear stress at the interface of the liquid metal and outgoing assist gas, $\mu$ is the viscosity of the liquid metal. $\tau_{i}$ can be estimated from the drag force, ${ }^{14,17}$ i.e.,

$$
\tau_{i}=\frac{1}{2} \rho_{g} v_{g}^{2} f_{g},
$$

where $\rho_{g}$ and $v_{g}$ are the density and the average velocity of the outgoing assist gas, respectively, and $f_{g}$ is the friction factor. The viscosity of the liquid metal $\mu$ can be estimated by the following expression: ${ }^{18,19}$

$$
\mu(T)=\mu_{0} \exp \left(\frac{E}{R_{g} T}\right)
$$

where $\mu_{0}$ is the preexponential viscosity and $E$ is the activation energy for viscous flow, which are both constants. $T$ is the absolute temperature of the liquid metal and $R_{g}$ is the universal gas constant.

When the assist gas jet enters into the cavity, it creates a stagnation point at the bottom of the cavity, and then the jet reverses its flow direction outward along the sidewall of the cavity. In other words, the assist gas jet is envisioned as flowing into the cavity along the central core of the cavity and then the jet flows out of the cavity through the annular region between the central incident assist gas jet and the sidewall of the cavity.

During the cavity formation, the liquid metal is removed by a combination of evaporation and melt expulsion. However, the mass fraction removed by evaporation is typically less than a tenth of the total mass removed. ${ }^{20,21}$ Also the cavity grows mainly in the $z$ direction compared to the $r$ direction, as shown in Fig. 1(a) (i.e., along the direction of laser beam propagation) during laser drilling. Therefore, neglecting the vaporization rate and considering the drilling speed in the $z$ direction, the following expression for the recast layer thickness $(\delta)$ can be obtained by combining Eqs. (5) and (16)-(18):

$$
\begin{aligned}
\delta= & \frac{1}{6 B_{3}}\left\{\left[-108 B_{2}+12 \sqrt{3}\left(\frac{4 B_{1}^{3}+27 B_{2}^{2} B_{3}}{B_{3}}\right)^{1 / 2}\right] B_{3}^{2}\right\}^{1 / 3} \\
& -\left\{\left[-108 B_{2}+12 \sqrt{3}\left(\frac{4 B_{1}^{3}+27 B_{2}^{2} B_{3}}{B_{3}}\right)^{1 / 2}\right] B_{3}^{2}\right\}^{1 / 3},
\end{aligned}
$$

where

$$
B_{1}=A I, \quad B_{2}=k_{l}\left(T_{\mathrm{st}}-T_{m}\right),
$$

and

$$
B_{3}=\frac{\rho_{l} C_{\mathrm{pl}} \tau_{i}\left(T_{\mathrm{st}}+T_{m}\right)}{2 \mu\left(R_{o}-R_{i}\right)} .
$$

Similarly, by considering the motion of the melting front to be mainly in the $z$ direction compared to the $r$ direction, Eqs. (3), (11), and (16) can be combined to obtain the following expression for the depth of the melting front:

$$
S_{m}(r, t)=\int_{0}^{t} \frac{k_{l}\left(T_{\mathrm{st}}-T_{m}\right)}{\delta\left[\frac{k_{s}}{\alpha_{s}}\left(T_{m}-T_{0}\right)+\rho_{s} L_{m}\right]^{d t} .}
$$

\section{RESULTS AND DISCUSSION}

The above mathematical model was used to investigate the effects of various process parameters such as laser intensity, pulse-on time, intensity profile, and annular beam radius. Inconel 718 was used as the substrate. The values of the material properties, ${ }^{22-24}$ laser parameters, and $\mathrm{O}_{2}$ assist gas properties ${ }^{17,25}$ used for this study are listed in Table I. Three types of annular intensity profiles have been used in this study.

TABLE I. Material properties of Inconel 718, laser parameters, and $\mathrm{O}_{2}$ assist gas used for this study.

\begin{tabular}{lc}
\hline \hline Substrate material & Inconel 718 \\
\hline Density of solid, $\rho_{s}\left(\mathrm{kgm}^{-3}\right)$ & 7840 \\
Density of liquid, $\rho_{l}\left(\mathrm{~kg} / \mathrm{m}^{3}\right)$ & 7250 \\
Thermal conductivity of solid, $k_{s}(\mathrm{~W} / \mathrm{cm} \mathrm{K})$ & 0.196 \\
Thermal conductivity of liquid, $k_{l}(\mathrm{~W} / \mathrm{cm} \mathrm{K})$ & 0.246 \\
Melting temperature, $T_{m}(\mathrm{~K})$ & 1623 \\
Boiling temperature, $T_{b}(\mathrm{~K})$ & 3188 \\
Specific heat capacity of solid, $C_{\mathrm{ps}}(\mathrm{J} / \mathrm{kg} \mathrm{K})$ & 569 \\
Effective specific heat capacity, $C_{\mathrm{eff}}(\mathrm{J} / \mathrm{kg} \mathrm{K})$ & 658 \\
Latent heat of melting, $L_{m}(\mathrm{~kJ} / \mathrm{kg})$ & 145 \\
Latent heat of boiling, $L_{v}(\mathrm{~kJ} / \mathrm{kg})$ & 6400 \\
Absorptivity, $A$ & 0.27 \\
Preexponential viscosity $\eta\left(T_{m}\right)(\mathrm{mPa} \mathrm{s})$ & 4.9 \\
Activation energy $E$ for viscous flow $(\mathrm{kJ} / \mathrm{mol})$ & 50.2 \\
Nd:YAG laser wavelength, $\lambda(\mu \mathrm{m})$ & 1.064 \\
Outer radius of the laser beam, $R_{o}(\mu \mathrm{m})$ & 85 \\
Density of assist gas, $\rho_{g}\left(10^{-3} \mathrm{~g} / \mathrm{cm}{ }^{3}\right)$ & 1.3007 \\
Gas flowrate, $f_{\mathrm{g}}\left(\mathrm{m}^{3} / \mathrm{h}\right)$ & 1.325 \\
Gas flow velocity, $V_{\mathrm{g}}(\mathrm{m} / \mathrm{s})$ & 300 \\
Nozzle exit diameter, $d_{n}(\mathrm{~mm})$ & 1.25 \\
\hline \hline
\end{tabular}




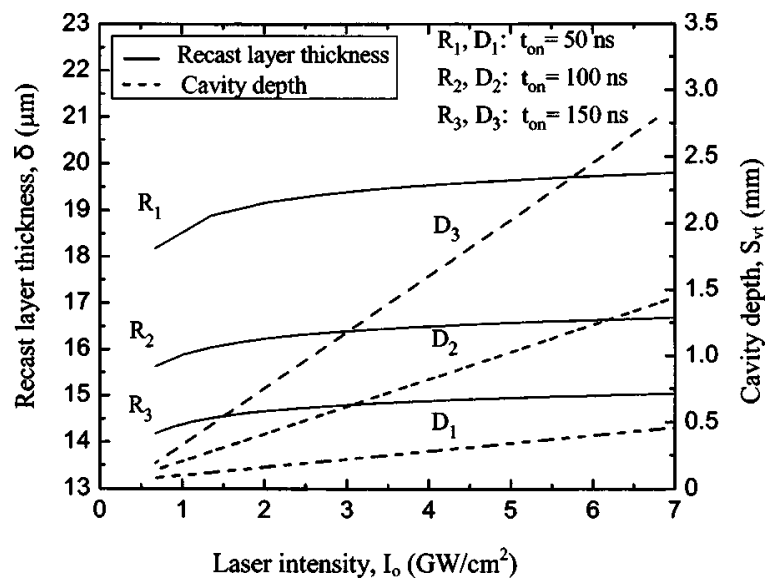

FIG. 2. Variation of recast layer thickness and cavity depth with laser intensity for full Gaussian annular beam $\left(f=1 \mathrm{kHz}, t_{\text {on }}=100 \mathrm{~ns}\right.$, drilling time $(t)=100 \mathrm{~ms}, R_{o}=85 \mu \mathrm{m}$, and $\left.R_{i}=65 \mu \mathrm{m}\right)$.

\section{A. Recast layer and cavity depth}

Figure 2 shows the variation of the maximum recast layer thickness and cavity depth at the bottom of the cavity with the laser intensity at the drilling time of $t=100 \mathrm{~ms}$ for various laser-pulse-on times. The results exhibit a common trend, i.e., the recast layer thickness and the cavity depth increase with the increase in the laser intensity. This is because the material melting rate is higher with the increase in the laser intensity causing more melting of materials. Much of the melt is expelled from the cavity by the assist gas, which leads to a steady-state condition when the melting and melt expulsion rates are equal. The recast layer thickness increases when the melting rate is higher than the expulsion rate. The effects of laser-pulse-on time on the recast layer thickness are significant, as shown in Fig. 2. Generally, the recast layer thickness decreases rapidly with the increase in the laser-pulse-on time, because more material is melted during each laser pulse and the melt is expelled by the assist gas efficiently. This produces thinner recast layer and deeper cavity depth.

Figure 3 shows the variation of the maximum recast layer thickness and cavity depth at the bottom of the cavity

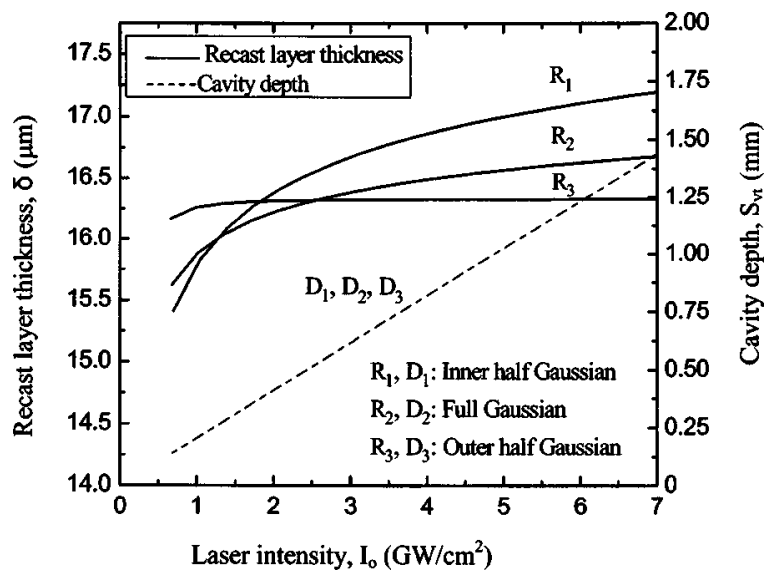

FIG. 3. Variation of recast layer thickness and cavity depth with laser intensity $\left(f=1 \mathrm{kHz}, t_{\mathrm{on}}=100 \mathrm{~ns}\right.$, drilling time $(t)=100 \mathrm{~ms}, R_{o}=85 \mu \mathrm{m}$, and $R_{i}=65 \mu \mathrm{m}$.)

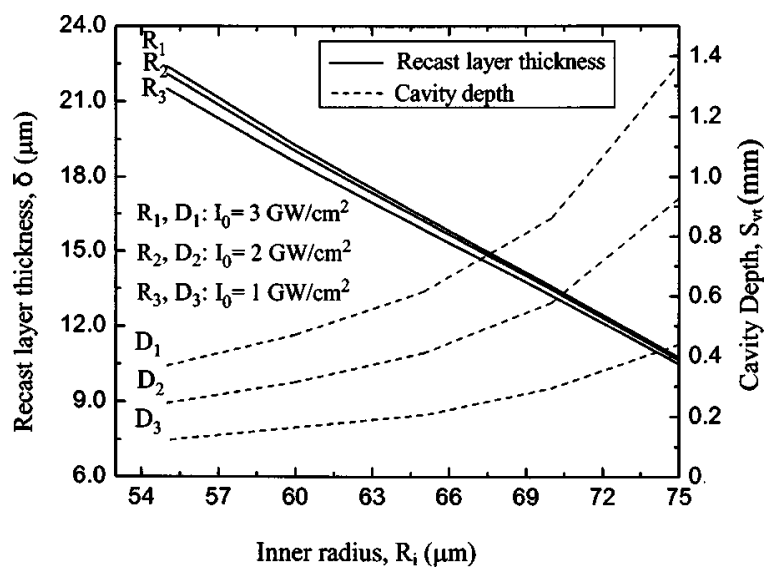

FIG. 4. Variation of recast layer thickness and cavity depth with inner radius of the annular laser beam for full Gaussian annular beam $\left(f=1 \mathrm{kHz}, t_{\mathrm{on}}\right.$ $=100 \mathrm{~ns}$, drilling time $(t)=100 \mathrm{~ms}$, and $\left.R_{o}=85 \mu \mathrm{m}\right)$.

with the laser intensity at the drilling time of $t=100 \mathrm{~ms}$ for various laser intensity profiles. The recast layer thickness and the cavity depth increase with the increase in the laser intensity for three types of intensity profiles. These three intensity profiles generate the same maximum cavity depth. For high laser intensities, the inner half Gaussian beam produces the thickest recast layer and the outer half Gaussian beam produces the thinnest recast layer. This is because more melting occurs at the inner circumference of the annulus for the inner half Gaussian beam compared to the amount of melting in the other two types of intensity profiles, and the assist gas is less effective in removing the melt in the former case.

Figure 4 shows the variation of the maximum recast layer thickness and the cavity depth at the bottom of the cavity with the inner radius of the annular beam at the drilling time of $t=100 \mathrm{~ms}$ for various laser intensities. The recast layer thickness decreases linearly and the cavity depth increases as the inner radius of the annular beam increases. This is because the melt front propagates more along the depth direction than along the radial direction as the inner radius of the annular beam increases. The melt is expelled by the assist gas efficiently, causing thinner recast layer and deeper cavity depth. Compared to the effects of laser intensity in Fig. 3, the effects of the inner radius of the annular beam are more significant, because the width of the annulus decreases for higher inner radius of the annular beam, resulting in lower melt volume to produce holes of a given depth than in the case of lower inner radius.

\section{B. Taper}

A measure of the taper of laser-drilled holes is the hole diameter ratio $D_{\mathrm{hi}} / D_{\mathrm{ho}}$, where $D_{\mathrm{hi}}$ is the hole diameter at the top surface of the workpiece on which the laser beam is incident and $D_{\text {ho }}$ is the hole diameter at the bottom of the workpiece. This diameter ratio, which is referred to as taper in this study, is plotted in Figs. 5-7. Perfectly cylindrical holes are drilled when $D_{\mathrm{hi}} / D_{\mathrm{ho}}=1 . D_{\mathrm{hi}} / D_{\mathrm{ho}}>1$ indicates convergent, i.e., convergent, nozzle-shaped holes and $D_{\mathrm{hi}} / D_{\mathrm{ho}}<1$ implies divergent, i.e., divergent, nozzle-shaped holes. 


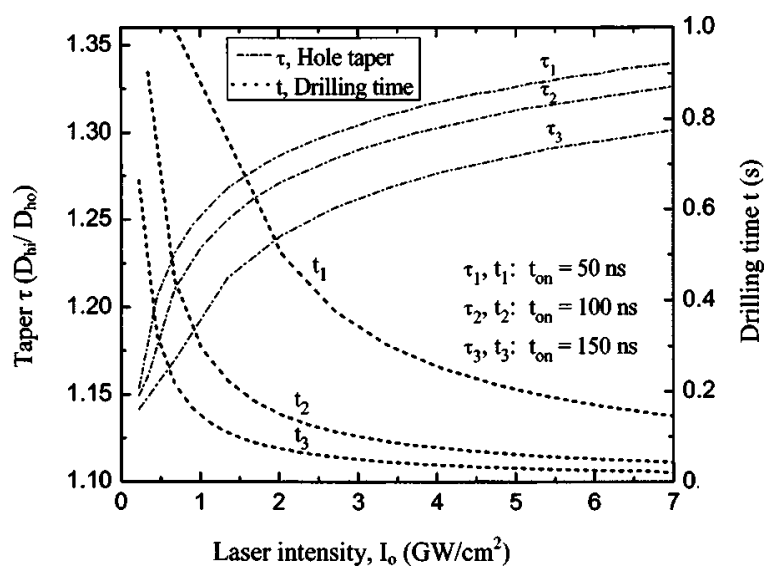

FIG. 5. Variation of taper with the laser intensity for full Gaussian annular beam $\left(S_{\mathrm{vt}}=632 \mu \mathrm{m}, t_{\mathrm{on}}=100 \mathrm{~ns}, f=1 \mathrm{kHz}, t_{\mathrm{on}}=100 \mathrm{~ns}, R_{o}=85 \mu \mathrm{m}\right.$, and $R_{i}$ $=65 \mu \mathrm{m})$.

Figure 5 shows the variation of taper and laser drilling time with the laser intensity for various laser-pulse-on times for laser-drilled holes with a depth of $632 \mu \mathrm{m}$. The increase in the laser-pulse-on time or the laser intensity reduces the drilling time, but increases the hole taper. This is because more melt is produced as the laser intensity increases, resulting in a thicker melt layer in the radial direction. Generally the assist gas is ineffective in removing the melt from the bottom portion of blind holes. This decreases the hole diameter at the bottom of the workpiece, forming more tapered holes. Similarly, thicker melt layer in the radial direction with the increase in the laser-pulse-on time results in more tapered holes.

Figure 6 shows the variation of taper and laser drilling time with the laser intensity for different intensity profiles for laser-drilled holes with a depth of $632 \mu \mathrm{m}$. Full Gaussian annular beams and inner half Gaussian annular beams generate convergent holes $\left(D_{\mathrm{hi}} / D_{\mathrm{ho}}>1\right)$, i.e., the hole diameter decreases along the depth direction. Outer half Gaussian annular beams generate divergent holes $\left(D_{\mathrm{hi}} / D_{\mathrm{ho}}<1\right)$, i.e., the hole diameter increases along the hole depth. This is because the maximum laser intensity occurs inside the annular region for the full Gaussian annular beam and at the inner circumference of the annulus for the inner half Gaussian annular

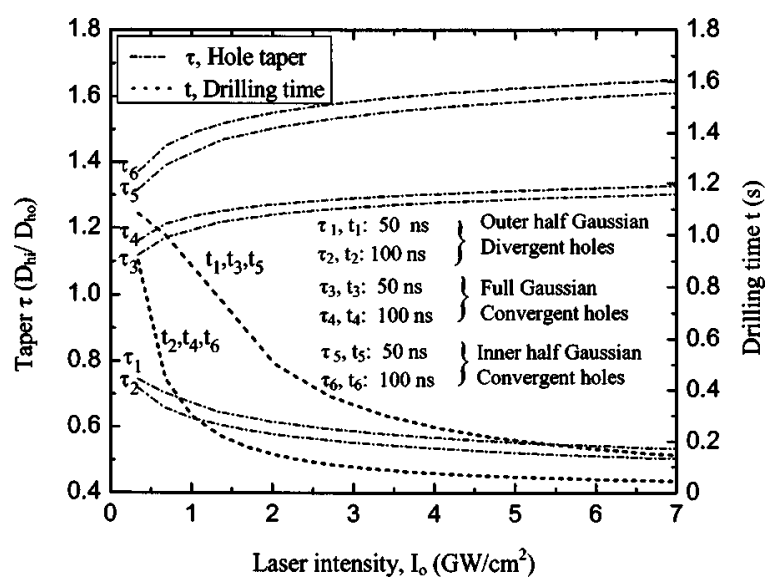

FIG. 6. Variation of taper with laser intensity for different laser intensity profiles $\left(S_{\mathrm{vt}}=632 \mu \mathrm{m}, t_{\mathrm{on}}=100 \mathrm{~ns}, f=1 \mathrm{kHz}, R_{o}=85 \mu \mathrm{m}\right.$, and $\left.R_{i}=65 \mu \mathrm{m}\right)$.

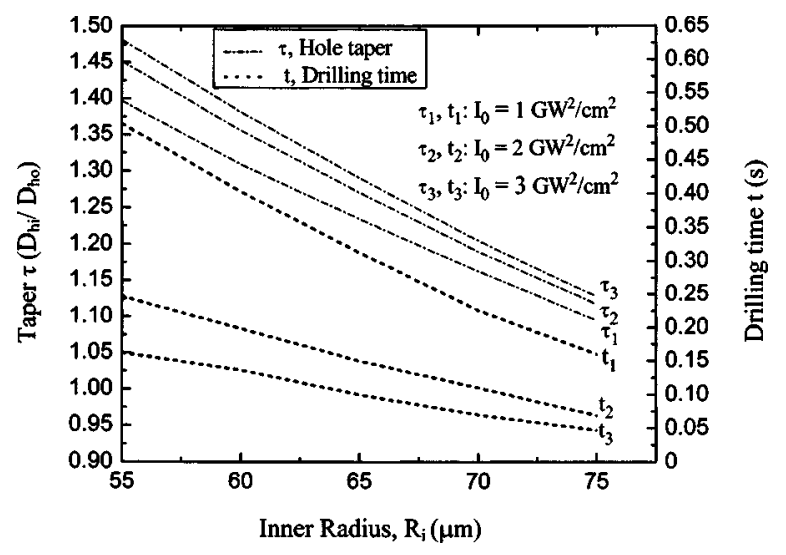

FIG. 7. Variation of taper with the inner radius of annular beam for full Gaussian annular beam $\left(S_{\mathrm{vt}}=632 \mathrm{~mm}, t_{\mathrm{on}}=100 \mathrm{~ns}, f=1 \mathrm{kHz}\right.$, and $R_{o}$ $=85 \mu \mathrm{m})$.

beam, which causes higher melting rate along the thickness of the workpiece in these two regions of the annulus. Thus a convergent hole is formed when the workpiece is melted preferentially in these two regions over its entire thickness. On the other hand, the maximum laser intensity occurs at the outer circumference of the annulus for the outer half Gaussian annular laser beam, leading to the divergent holes.

Figure 7 shows the variation of taper and drilling time with the inner radius of annular beam for different laser intensities for laser-drilled holes with a depth of $632 \mu \mathrm{m}$. The taper formation in optical trepanning is reduced significantly by increasing the inner radius of an annular beam. This is because smaller melt volume is produced as the inner radius of an annular beam increases, forming thinner recast layer leading to less tapered holes. Compared to the effects of laser-intensity and laser-pulse-on time, the effects of the inner radius of the annular beam are more significant because the melt front propagates in the radial direction more than in the former two cases. An increase in the laser intensity or the laser-pulse-on time widens the melt front in the radial direction due to more energy input to the workpiece. For very short laser-pulse-on time, the heat conduction along the radial direction is limited and the melt front propagates a small distance in the radial direction.

The tapers shown in Figs. 5-7 are large (e.g., $\tau>1.1$ for a full Gaussian annular beam) because our model is based on the blind hole geometry and the tapers have been calculated by considering the recast layer thickness at the bottom of the cavity. Optical trepanning is expected to produce holes with less tapers for through holes, because in such cases, the melt can be removed efficiently by the assist gas through the bottom of the workpiece. This will reduce the differences in the hole diameters at the top and bottom surfaces of the workpiece and produce less tapered holes.

\section{CONCLUSIONS}

An analytic two-dimensional model is developed for optical trepanning. The analysis accounts for conduction in the solid, vaporization, convection due to the melt flow and the effects of an assist gas. On the basis of the results ensuing 
from the present study dealing with pulsed Nd:YAG laser optical trepanning of IN 718 material, the following conclusions can be drawn:

(1) The effects of annular beam radius are significant in most cases. It significantly influences the drilling hole qualities due to the widening of the melt layer in the radial direction. For a fixed outer radius of an annular beam, thinner recast layer, smaller taper, and higher drilling speed are obtained with the increase in the inner radius of the annular beam.

(2) By using different types of intensity profiles, the nature of the hole taper can be modified, i.e., convergent or divergent holes can be produced. Full Gaussian beam and inner half Gaussian beam generate convergent holes and outer half Gaussian beam produces divergent holes. This shows that annular beams can provide more flexibility in affecting the hole quality than tradition circular beams since an annular beam allows numerous irradiance profiles to supply laser energy to the workpiece.

(3) An increase in the laser intensity generates thicker recast layer, deeper cavity depth, and larger taper.

(4) An increase in the laser-pulse-on time generates thinner recast layer, deeper cavity depth, and larger taper.

\section{ACKNOWLEDGMENTS}

This research was supported by Laser Fare, Inc., Smithfield, Rhode Island, under a SBIR Phase II project on laser drilling supported by Air Force Research Laboratory, Albuquerque, New Mexico, USA. Dr. W. P. Latham is the program manager who proposed the optical trepanning concept.

${ }^{1}$ J. F. Ready and D. F. Farson, LIA Handbook of Laser Material Processing
(Magnolia Publishing, Orlando, 2001), pp. 471-512.

${ }^{2}$ Th. Beck, G. Bostanjoglo, N. Kugler, K. Richter, and H. Weber, in Proceedings of the 1997 Laser Materials Processing Conference, ICALEO'97, edited by R. Fabbro, A. Kar, and A. Matsunawa (Laser Institute of America, San Diego, California, 1997), Sec. E, pp. 93-102.

${ }^{3}$ S. Bandyopadhyay, J. K. Sarin Sundar, G. Sundararajan, and S. V. Joshi, J. Mater. Process. Technol. 127, 83 (2002).

${ }^{4}$ B. S. Yilbas, J. Mater. Process. Technol. 70, 264 (1997).

${ }^{5}$ X. Chen, W. T. Lotshaw, A. L. Ortiz, P. R. Staver, C. E. Erikson, M. H. Mclaughlin, and T. J. Rockstroh, J. Laser Appl. 8, 233 (1996).

${ }^{6}$ D. K. Y. Low, L. Li, and A. G. Corfe, J. Mater. Process. Technol. 118, 179 (2001).

${ }^{7}$ G. Ng and L. Li, Opt. Laser Technol. 33, 393 (2001).

${ }^{8}$ M. Ghoreishi, D. K. Y. Low, and L. Li, Int. J. Mach. Tools Manuf. 42, 985 (2002).

${ }^{9}$ K. T. Voisey, S. S. Kudesia, W. S. O. Rodden, D. P. Hand, J. D. C. Jones, and T. W. Clyne, Mater. Sci. Eng., A 356, 414 (2003).

${ }^{10}$ G. Kamlage, T. Bauer, A. Ostendorf, and B. N. Chichkov, Appl. Phys. A: Mater. Sci. Process. 77, 307 (2003).

${ }^{11}$ M. Rioux, R. Tremblay, and P. A. Belanger, Appl. Opt. 17, 1532 (1978).

${ }^{12}$ P. A. Belanger and M. Rioux, Appl. Opt. 17, 1080 (1978).

${ }^{13}$ A. Kar and J. Mazumder, J. Appl. Phys. 68, 3884 (1990).

${ }^{14}$ A. Kar, T. Rockstroh, and J. Mazumder, J. Appl. Phys. 71, 2560 (1992).

${ }^{15}$ S. Sankaranarayanan, H. Emminger, and A. Kar, J. Phys. D 32, 1605 (1999).

${ }^{16}$ M. N. Ozisik, Heat Conduction (Wiley, New York, 1993).

${ }^{17}$ R. B. Bird, W. E. Stewart, and E. N. Lightfoot, Transport Phenomena (Wiley, New York, 1960), pp. 23-25, 180-187.

${ }^{18}$ Z. B. Sylvan, Liquid Metals Chemistry and Physics (Marcel Dekker, New York, 1972), pp. 431-457.

${ }^{19}$ J. A. Spittle and S. G. R. Brown, Acta Metall. 37, 1791 (1989).

${ }^{20}$ W. R. Smith, SIAM J. Appl. Math. 62, 1899 (2002).

${ }^{21} \mathrm{M}$. Allmen and A. Blatter, Laser-Beam Interactions with Materials (Springer Berlin, 1995), pp. 131-134.

${ }^{22}$ C. L. Mantell, Engineering Materials Handbook (McGraw-Hill Book Company, New York, 1958), pp. 1-30.

${ }^{23}$ G. Pottlacher, H. Hosaeus, E. Kaschnitz, and A. Seifter, Scand. J. Metall. 31, 161 (2002).

${ }^{24}$ D. Basak, R. A. Overfelt, and D. Wang, Int. J. Thermophys. 24, 1721 (2003).

${ }^{25}$ D. K. Y. Low, L. Li, and P. J. Byrd, J. Manuf. Sci. Eng. 124, 852 (2002). 